\title{
Crystal Structure of Diisopropylammonium Hydrogen Maleate
}

\author{
Dame Seye $^{1,}$, , Assane Toure ${ }^{1}$, Momath Lo ${ }^{2}$, Cheikh Abdoul Khadir Diop ${ }^{1}$, Libasse Diop ${ }^{1}$, \\ David Geiger ${ }^{3}$ \\ ${ }^{1}$ Mineral and Analytical Chemistry Laboratory, Department of Chemistry, Faculty of Science and Technology, Cheikh Anta Diop University, \\ Dakar, Senegal \\ ${ }^{2}$ Laboraory of Organic Physical Chemistry Instrumental Analysis, Department of Chemistry, Faculty of Science and Technology, Cheikh Anta \\ Diop University, Dakar, Senegal \\ ${ }^{3}$ Department of Chemistry, Geneseo Faculty, State University of New York, Geneseo, New York, USA
}

\section{Email address:}

maviemama2010@yahoo.fr (D. Seye)

${ }^{*}$ Corresponding author

\section{To cite this article:}

Dame Seye, Assane Toure, Momath Lo, Cheikh Abdoul Khadir Diop, Libasse Diop, David Geiger. Crystal Structure of Diisopropylammonium Hydrogen Maleate. Science Journal of Chemistry. Vol. 7, No. 6, 2019, pp. 110-113. doi: 10.11648/j.sjc.2019070612

Received: January 7, 2020; Accepted: January 29, 2020; Published: February 11, 2020

\begin{abstract}
Use of salts and co-crystals of active pharmaceutical ingredients (APIs) as a method for tuning their delivery and activity is an area of growing interest. Modifying API properties such as solubility by finding new salts that employ similar hydrogen-bonding have been successful. In an effort to further study the hydrogen-bonding patterns of the maleate ion with other diisopropylammonium we report here the synthesis and diisopropylammonium maleate. The salt was isolated from reaction between diisopropylamine and maleic acid in methanol. The results of elementary analyzes (CHN) showed the presence of the nitrogen atom of diisopropylamine, carbon atoms and hydrogen. The IR spectrum of diisopropylammonium hydrogen maleate, showed the presence of two intense bands due to the vibrations of symmetricand anti-symmetric valence of the carboxylate group and a wide absorption due to the $\mathrm{NH}_{2}$ groups of the cation. Those which has been confirmed by crystallography. The asymmetric unit contains one diisopropylammonium cation, $\mathrm{iPr}_{2} \mathrm{NH}_{2}{ }^{+}$and one hydrogen maleate anion. In the structure, anions which present an inner $\mathrm{O}-\mathrm{H} \ldots \mathrm{O}$ hydrogen bond are linked to cations through $\mathrm{N}-\mathrm{H} \ldots \mathrm{O}$ hydrogen bonds leading to infinite chains. Chains are connected to their neighbours through weak C-H...O hydrogen bonds affording a layer. The study of the interactions of diisopropylammonium hydrogen menaleate, by the presence of hydrogen bonds leading to supramolecular architectures has shown the possibility of its use in Active Pharmaceutical Ingrédients (API).
\end{abstract}

Keywords: Crystal Structure, Diisopropylammonium, Maleate, Hydrogen Bonds, Sheet

\section{Introduction}

Various ammonium salts of maleic acid have been synthesized and structurally characterized [1-6]. Use of salts and co-crystals of active pharmaceutical ingredients (APIS) as a method for tuning their delivery and activity is an area of growing interest [6]. Modifying API properties such as solubility by finding new salts that employ similar hydrogen bonding have been successful. Maleate derivatives remain among the agents most used in the design of active pharmaceutical ingredients (APIs) because of its power to give APIs a high solubility. Recently, Timolol maleate has been developed and validated as being safe and effective APIs in the treatment of ocular glaucoma [7, 8]. Enalapril maleate has been successfully designated and evaluated according to the United States Pharmacopoeia (USP) for the treatment of hypertensive diseases [9]. For example, in the conext of improving the solubility of this drug, three saccharinate, maleate and oxalate salts of Ethionamide (ETH) have been synthesized [1]. Mechanochemical protocols, confirmed by powder X-ray diffraction, sheew a more complete solid state characteriszation for Ethionamide (ETH) maleate [1]. 
Whenever possible, Active Pharmaceutical Ingredients (APIs) having properties of increasing solubility by the presence of its hydrogen bonds like maleate should be selected for the formation of the optimal salt. In an effort to further study of the hydrogen bonding patterns of the maleate ion with another ammonium counter cation nous avons synthétisé le diisopropylammonium hydrogen maleate. Diisopropylammonium comes from diisoprylamine which was used recently with dichloroacetate as being alleviates liver fibrosis through inhibiting activation and proliferation of hepatic stellate cells [10], we investigated the interactions between diisopropylamine and maleic acid which yielded single crystals of diisopropylammonium hydrogen maleate, $\left\{\left[i \mathrm{PrNH}_{2}\right]^{+} .\left[\mathrm{HCO}_{2} \mathrm{CH}=\mathrm{CHCO}_{2}\right]^{-}\right\} \quad$ whose crystallographic characterization is reported herein.

\section{Materials and Methods}

\subsection{General}

Chemicals were purchased from Sigma-Aldrich (Germany) and were used without any further purification. Elemental analyses were performed at the Institut de Chimie Moléculaire, Université de Bourgogne Franche-Comté, Dijon, France. The infrared spectra were recorded on a Bruker Vector 22 spectrometer equipped with a Specac Golden Gate ${ }^{\mathrm{TM}}$ ATR device. A crystal of dimensions $0.60 \times 0.32 \times 0.16 \mathrm{~mm}$ was used in the data collection. The structure has been resolved and refined using the SAINT V8.37A programs (Bruker AXS Inc., 2015), XT VERSION 2014/5 [11, 12].

\subsection{Synthesis}

All the chemicals were purchased from Aldrich Company (Germany) and used without any further purification. Maleic acid, $\mathrm{HCO}_{2} \mathrm{CH}=\mathrm{CHCO}_{2} \mathrm{H}(5.00 \mathrm{~g}, 43 \mathrm{mmol})$ was partially neutralized with diisopropylamine, $i \mathrm{Pr}_{2} \mathrm{NH}(4.38 \mathrm{~g}, 43 \mathrm{mmol})$ in methanol $(50 \mathrm{~mL})$. The clear obtained mixture was stirred $2 \mathrm{~h}$ at room temperature $(300 \mathrm{~K})$. Crystals of the title salt suitable for an X-ray diffraction analysis was obtained after a month of a slow solvent evaporation at room temperature (300 $\mathrm{K})$.

Table 1. Results of the elemental analyses of diisopropylammonium hydrogen maleate.

\begin{tabular}{|c|c|c|c|c|c|c|c|}
\hline \multirow{3}{*}{ Compound } & \multirow{3}{*}{ Chemical formula } & \multicolumn{6}{|c|}{ Elemental analysis [\%] } \\
\hline & & \multicolumn{2}{|l|}{$\mathbf{C}$} & \multicolumn{2}{|l|}{$\mathbf{H}$} & \multicolumn{2}{|l|}{$\mathbf{N}$} \\
\hline & & Calc. & Found & Calc. & Found & Calc. & Found \\
\hline $\mathrm{A}$ & $\left\{\left[i \mathrm{PrNH}_{2}\right]^{+}\left[\mathrm{HCO}_{2} \mathrm{CH}=\mathrm{CHCO}_{2}\right]^{-}\right\}$ & 72,06 & 71,80 & 9,40 & 8,60 & 8,85 & 8,75 \\
\hline
\end{tabular}

\section{Structure Description}

\subsection{Spectroscopic Study}

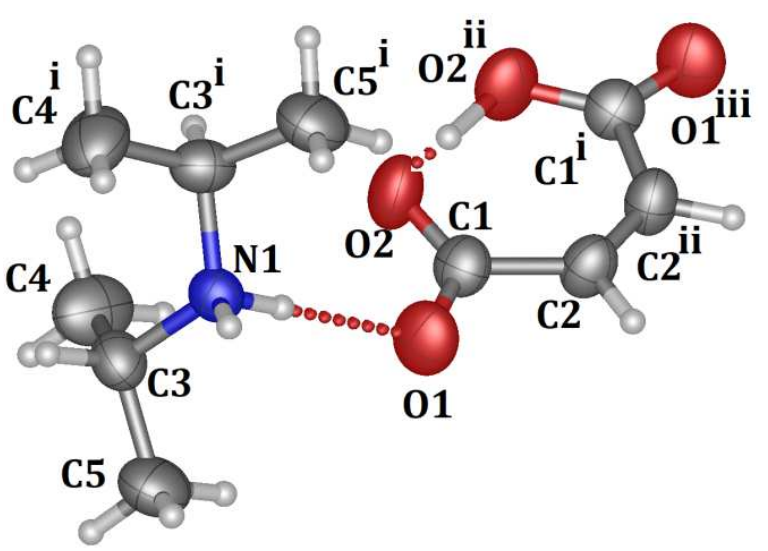

Figure 1. Asymmetric unit of diisopropylammonium hydrogeno maleate.

The table 2 shown the Infrared data of diisopropylammonium hydrogen maleate. Compound diisopropylammonium hydrogen maleate was investigated by FT-IR spectroscopy. In the past, several works with FT-IR diisopropylammonium cations, carboylates anions and multiples other vibration bands investigation have been reported [13]. The infrared spectrum enables to diagnose $\mathrm{N}-\mathrm{H}$ stretching and bending vibrations at $3385 \mathrm{~cm}^{-1}, 3251 \mathrm{~cm}^{-1}$ and $11619 \mathrm{~cm}^{-1}$, CO antisymmetric and symmetric vibrations at $1548 \mathrm{~cm}^{-1}, 1576 \mathrm{~cm}^{-1}$ and $1318 \mathrm{~cm}^{-1}$. The band around 1619 $\mathrm{cm}^{-1}$ is due to the anti-symmetrical vibration of the $\mathrm{NH}_{2}$ group. This shows the presence of a maleate anion and a diisopropylammonium cation, confirmed by data from the asymmetric unit of the molecule shown in the following (figure 1).

\subsection{Crystallographic Study}

The title salt crystallizes in the orthorhombic Pccn space group as colourless plate-like crystals with parameters a = 9.6312 (16), b = 11.188 (2), c = 11.7591 (15) (table 3). Its asymmetric unit is comprised of one diisopropylammonium cation and one hydrogen maleate (Figure 1). Several crystals of salts containing the diisopropylammonium cation, $i \mathrm{PrNH}_{2}{ }^{+}$ are isolated and their structures reported in the literature [14, $15,16,17,18]$.

In the structure, the acid anions $\mathrm{H}_{2} \mathrm{OC}-\mathrm{CH}=\mathrm{CH}-\mathrm{CO}_{2}{ }^{-}$are linked together by cations via hydrogen bonds $\mathrm{OH}$ ' $\mathrm{O}$, $\mathrm{NH} \cdot$ O giving rise to zigzag chains parallel to [010] (Figure 2) in which cations and anions alternate.

The geometric parameters (bond lengths and angles) of the ${ }_{i} \mathrm{Pr}_{2} \mathrm{NH}_{2}{ }^{+}$cation in the studied salt are well in accordance with those previously reported for other carboxylate salts such as bis(diisopropylaminium) hydrogen 1,2,3,4-butane tetracarboxylate $\left[\left(\mathrm{Hdpa}^{+}\right)_{2} \cdot\left(\mathrm{H}_{2} \mathrm{Bta}^{2-}\right), \mathrm{H}_{2} \mathrm{Bta}^{2-}=\right.$ dihydrogen 1,2,3,4-butane tetracarboxylate] and diisopropylaminium hydrogen1,2-phenylenediacetate[(Hdpa).(Hpda $), \mathrm{Hpda}^{-}=$ hydrogen 1,2-phenylenediacetate] [17]. Maleate salts with diverse counter cations are also widely reported in the literature $[2,3,5]$. Bond lengths and angles within the maleate are in the expected range $[2,3,5]$. 


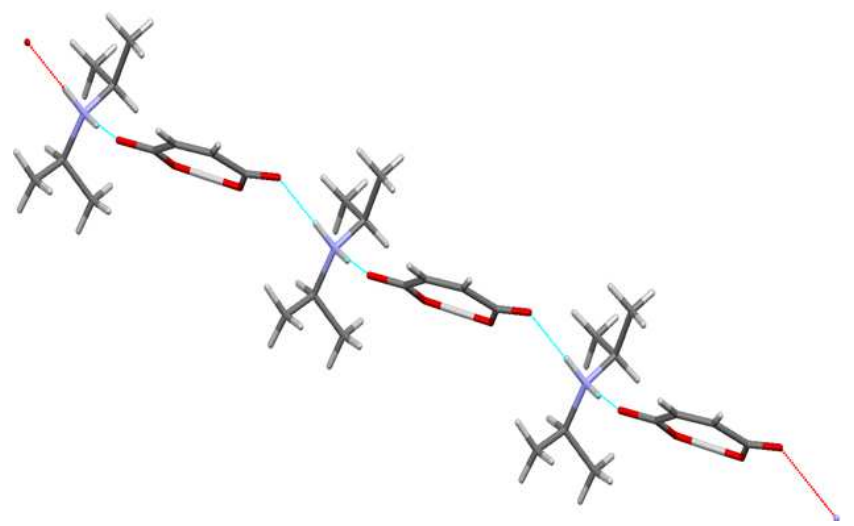

Figure 2. Hydrogen bonds $(\mathrm{N}-\mathrm{H} \cdot \mathrm{O})$ along axis a.

In the structure, the acid anions $\mathrm{HO}_{2} \mathrm{C}-\mathrm{CH}=\mathrm{CH}-\mathrm{CO}_{2}$ - are linked together by cations via hydrogen bonds $\mathrm{OH}$. $\mathrm{O}$, $\mathrm{NH}$ * O giving rise to zigzag chains parallel to [010] (Figure 2) in which the cations and anions alternate. If we visualize approximately these interactions along the $\mathrm{C}$ axis, we observe a superposition of chains in which the maleates and the diisopropylammonium cations are superimposed between them. The layers interact by Vader Wals type connections (Figure 3).

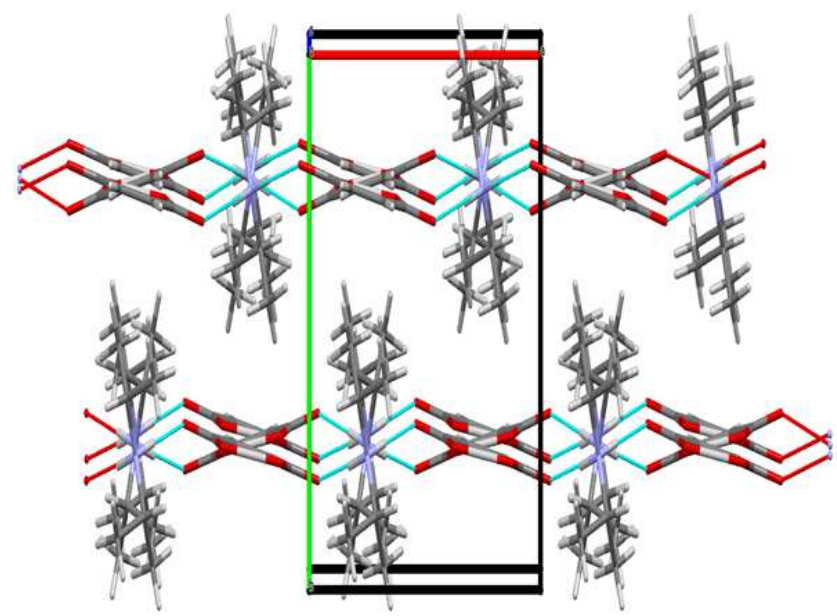

Figure 3. Hydrogen bonds $\mathrm{O}-\mathrm{H} \ldots \mathrm{O}, \mathrm{N}-\mathrm{H} \cdot \cdot \mathrm{O}$ seen approximately along the axis $c$.

Table 2. Infrared data of the characteristic bands of diisopropylammonium hydrogen maleate.

\begin{tabular}{lll}
\hline Compound & vasCOO- & vsCOO- \\
\hline$\left[i \mathrm{PrNH}_{2}\right]^{+}\left[\mathrm{HCO}_{2} \mathrm{CH}=\mathrm{CHCO}^{-}\right.$ & $\begin{array}{l}1548(\mathrm{~m}) \\
1576(\mathrm{~m})\end{array}$ & $1318(\mathrm{~m})$ \\
\hline & & \\
\hline $\boldsymbol{\delta C O O}-$ & $\mathbf{v}\left(\mathbf{N H}_{2}\right)$ & vas(NH$)$ \\
\hline $835(\mathrm{~m})$ & $3251(\mathrm{~m})$ & $1619(\mathrm{~s})$ \\
\hline
\end{tabular}

A search of the Cambridge Structural Database (CSD Version 5.41, Update November 2019; Groom et al., 2016) [19]. yielded 67 hits for diisopropylammonium salts while more than 80 hits were obtained for the maleate anion. Within the maleate, a strong inner $\mathrm{O} 2-\mathrm{H} 2 \mathrm{~A} \cdots \mathrm{O} 2^{\mathrm{ii}}$ (Table 4) hydrogen bond link the two carboxylates. In the structure
${ }_{i P r} \mathrm{NH}_{2}{ }^{+}$cations and maleate anions are connected alternately through a $\mathrm{N} 1-\mathrm{H} 1 \mathrm{~A} \cdots \mathrm{O} 1$ hydrogen bond giving rise to an infinite chain. Weak $\mathrm{C} 4-\mathrm{H} 4 \mathrm{~A} \cdots \mathrm{O} 1$ (Table 4) link chains leading to a sheet structure (Figure 4).

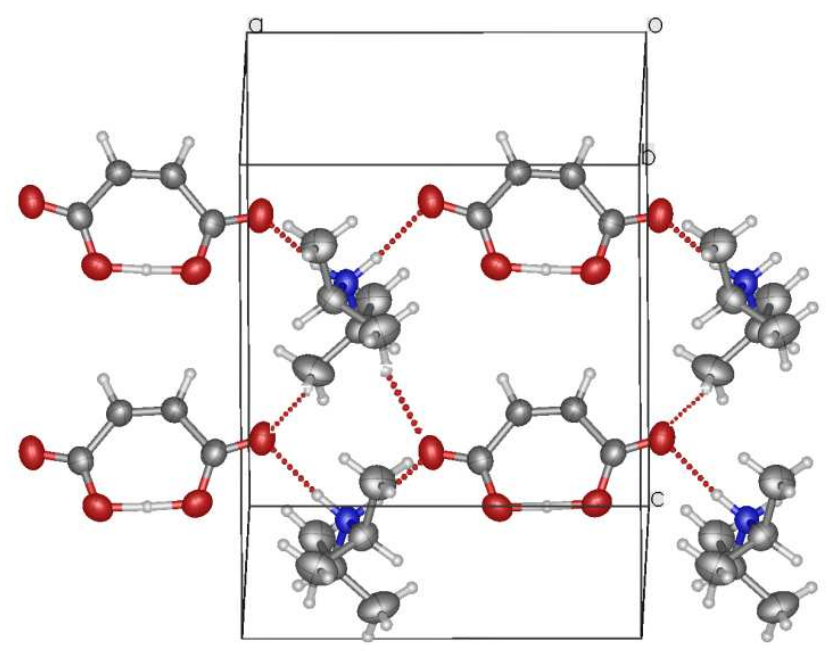

Figure 4. Partial packing diagram showing the hydrogen-bonding interactions.

CCDC 1975887 contains the supplementary crystallographic data for this paper. These data can be obtained free of charge from the Cambridge Crystallographic Data Centre via www.ccdc.cam.ac.uk/data_request/cif.

Table 3. Expérimental détails.

\begin{tabular}{|c|c|}
\hline \multicolumn{2}{|l|}{ Crystal data } \\
\hline Chemical formula & $\mathrm{C}_{10} \mathrm{H}_{19} \mathrm{NO}_{4}$ \\
\hline$M_{\mathrm{r}}$ & 217.26 \\
\hline Crystal system, space group & Orthorhombic, Pccn \\
\hline Temperature (K) & 200 \\
\hline$a, b, c(\AA)$ & $9.6312(16), 11.188(2), 11.7591(15)$ \\
\hline$V\left(\AA^{3}\right)$ & $1267.1(3)$ \\
\hline$Z$ & 4 \\
\hline Radiation type & $\lambda=0.71073 \AA$ \\
\hline$\mu\left(\mathrm{mm}^{-1}\right)$ & 0.09 \\
\hline Crystal size (mm) & $0.60 \times 0.32 \times 0.16$ \\
\hline \multicolumn{2}{|l|}{ Data collection } \\
\hline \multicolumn{2}{|l|}{ Diffractometer } \\
\hline Absorption correction & $\begin{array}{l}\text { Multi-scan } S A D A B S 2016 / 2 \text { - Bruker } \\
\text { AXS area detector scaling and } \\
\text { absorption correction }\end{array}$ \\
\hline$T_{\min }, T_{\max }$ & $0.64,0.99$ \\
\hline 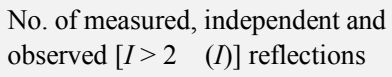 & $9187,1274,987$ \\
\hline$R_{\text {int }}$ & 0.056 \\
\hline$(\sin \theta / \lambda)_{\max }\left(\AA^{-1}\right)$ & 0.625 \\
\hline \multicolumn{2}{|l|}{ Refinement } \\
\hline$R\left[F^{2}>2 \sigma\left(\left(F^{2}\right)\right], w R\left(F^{2}\right), S\right.$ & $0.043,0.117,1.02$ \\
\hline No. of reflections & 1274 \\
\hline No. of parameters & 78 \\
\hline H-atom treatment & $\begin{array}{l}\mathrm{H} \text { atoms treated by a mixture of } \\
\text { independent and constrained } \\
\text { refinement }\end{array}$ \\
\hline$\left.\Delta\rangle_{\max }, \Delta\right\rangle_{\min }\left(\mathrm{e} \AA^{-3}\right)$ & $0.13,-0.15$ \\
\hline
\end{tabular}


Table 4. Hydrogen-bond geometry $\left(\AA,{ }^{\circ}\right)$ of diisopropylammonium hydrogen maleate.

\begin{tabular}{lll}
\hline$D-\mathrm{H} \cdots A$ & $D-\mathrm{H}$ & $\mathrm{H} \cdots A$ \\
$\mathrm{O} 2-\mathrm{H} 2 A \cdots \mathrm{O} 2^{\mathrm{ii}}$ & $1.21(1)$ & $1.21(1)$ \\
$\mathrm{N} 1-\mathrm{H} 1 A \cdots \mathrm{O} 1$ & $0.932(15)$ & $1.894(15)$ \\
$\mathrm{C} 4-\mathrm{H} 4 A \cdots \mathrm{O} 1^{\mathrm{iii}}$ & 0.98 & 2.54 \\
$D \cdots A$ & $D-\mathrm{H} \cdots A$ & \\
$2.413(2)$ & $177(3)$ & \\
$2.8186(15)$ & $171.5(13)$ & \\
$3.494(2)$ & 164 & \\
\hline
\end{tabular}

Symmetry codes: (ii) $-x+1 / 2,-y+1 / 2, z$; (iii) $x,-y+1 / 2, z+1 / 2$.

\section{Conclusion}

The structure of diisopropylammonium hydrogen maleate studied is an infinite chain deriving from hydrogen bonds of $\mathrm{N}-\mathrm{H}$... O and C-H... O type leading to a supramolecular structure. The study of these interactions has shown the possibility of using these salts in active pharmaceutical ingredients (APIs).

\section{Acknowledgements}

The authors gratefully acknowledge the Cheikh Anta Diop University - Dakar (Senegal), the University of Bourgogne Franche-Comté, Dijon (France) and the SUNY-College Geneseo - NY (USA) for facilities and financial supports.

\section{References}

[1] V. P. Cerreia, R. Chierotti, M and R. Gobetto, "Pharmaceutical aspects of salt and cocrystal forms of APIs and characterization challenges," Advanced. Drug. Deliver, vol. 117, pp. 86-110, August 2017.

[2] M. Maha, E. J. Daron, R. Mohamed and S. S. Wajda, "Crystal structure of 2,5-dimethylanilinium hydrogen maleate," Acta Cryst, vol. E70, pp. 1183-1184. October 2014.

[3] W. Intissar, V. Arto, R. Mohamed and S. S Wajda, "Crystal structure of 2-methylpiperazine-1,4-diium bis(hydrogen maleate),"Acta Cryst, vol. E71, pp. 193-194, March 2015.

[4] J. R. Guido and K. M. Michaela, "Bis(diisopropylammonium) sulfate," Acta Cryst, vol. E60, pp. o985-o98, May 2004.

[5] G. T. Gyula, M. V. Nóra, and B. Petra, "Crystal structure of levomepromazine maleate," Acta Cryst. Vol. E72, pp. 612-615, May, 2016.

[6] P. K. Steven, N. Asako, H. D. John, G. D. Keith, R. W. Matthew and R. D. Robin, "Understanding the Effects of Ionicity in Salts, Solvates, Co-Crystals, Ionic Co-Crystals, and Ionic Liquids, Rather than Nomenclature, Is Critical to Understanding Their Behavior,” Cryst. Growth Des, vol. 13, pp. 965-975 February, 2013.
[7] M. H. Rania, A. G. Heba, A. H. M. Salma, K. Noha, A. Toka, A Alaa, Y, Nesreen, N. Sandy, M and A. Abdel kader. "Gelatinized core liposomes: A new Trojan horse for the development of a novel timolol maleate glaucoma medication," International Journal of Pharm, vol. 5 56, pp. 192-199, February, 2019.

[8] B. P, Nagori, A, Maru, M. Pankaj and G. Subhash, "Method Development and Its Validation for Simultaneous Estimation of Timolol Maleate and Dorzolamide Hydrochloride in as API and in Ophthalmic Solution Dosage Form by RPHPLC," J. Chem. Pharm. Res, vol. 3, No. 4, 866-874, 2011.

[9] B. Rehana, S. N. Baqir, S. H. Mouhammad and R. Najia,"design and evaluation of a new formulation of enalapril maleate tablet,” Pak. J. Pharm. Sci, vol. 24, No. 2, pp. 211-215, April, 2011.

[10] C. Yan, X-Y. Wu, O-Y. Luo, L. Su, Y-T. Ding, Y. Jiang, D-C. Yu "Diisopropylamine dichloroacetate alleviates liver fibrosis through inhibiting activation and proliferation of hepatic stellate cells,” Int. J. Clin. Exp. Med. 2019, 12, 3440-3448.

[11] Bruker (2016). Apex3 v2016.9-0, Saint V8.34A, SAINT V8.37A, Bruker AXS Inc.: Madison (WI), USA, 2013/2014.

[12] G. M. Sheldrick (2015). (SHELXL2014/7). Acta Cryst. C71, 3-8.

[13] Nakamoto K. (1997). Infrared and Raman Spectra of Inorganic and Coordination Compounds, Edited by John Wiley and Sons, 5th Edition

[14] D. Seye, L. Diop, C. A. K. Diop and D. Geiger, "Diisopropylammonium hydrogen phthalate," Acta Cryst, IUCrData 3, x180704, May 2018.

[15] D. Seye, C. A. K. Diop L. Diop, and D. Geiger, "Diisopropylammonium benzenesulfonate," Acta Cryst. IUCrData 3, x180876, June 2018.

[16] R. J. Guido and M. K Michaela, "Synthesis and Structural Characterization of Diisopropylammonium Trifluoroacetate and Diisoproplyammonium Pentafluoropropionate," Z. Naturforsch. B Chem. Sci, vol. 65b, pp. 479-484, 2010.

[17] L. Zhihao, H. Kaikai, J. Shouwen, D. Aihua, W. Yining, D, Lingfeng, G. Xingjun and w. Daqi, "Crystal and molecular structures of sixteen charge-assisted hydrogen bond-mediated diisopropylammonium salts from different carboxylic acids," J. Mol. Struct, vol. 1146, pp. 577- 591, October 2017.

[18] A. Piecha-Bisiorek,, A. Gagor, D. Isakov,, P. Zielinski, M. Galazka and R. Jakubas, "Phase sequence in diisopropylammonium iodide: avoided ferroelectricity by the appearance of a reconstructed phase," Inorg. Chem. Front, vol. 4, pp. 553-558, January, 2017.

[19] C. R. Groom, I. J. Bruno, M. P. Lightfoot, and S. C. Ward, "The Cambridge Structural Database," Acta Cryst, vol. B72, pp. 171-179, March 2016. 